УДК 343.985 .2

\title{
А.А. Комоско
}

\section{ОТДЕЛЬНЫЕ ПРОБЛЕМЫ НАЗНАЧЕНИЯ НАКАЗАНИЯ И ПРИМЕНЕНИЯ ИНЫХ МЕР УГОЛОВНО-ПРАВОВОГО ХАРАКТЕРА ПО РОССИЙСКОМУ ЗАКОНОДАТЕЛЬСТВУ}

\begin{abstract}
Институт наказания и иных мер уголовно-правового характера имеет важное значение в развитии криминологии и уголовного права. Однако в научной литературе до настоящего времени отсутствует единое понимание отдельных юридических конструкций, что, безусловно, влияет на формирование ядра концепции наказания. В статье рассматриваются проблемы назначения и применения иных мер уголовно-правового характера. Автором на основе анализа научных работ специалистов в этой области делаются выводы, позволяющие оптимизировать категориальный аппарат, используемый в правоприменении. Приводится новый подход к раскрытию термина «наказание», обосновывается позиция, согласно которой институт наказания может быть изучен только сквозь призму корреляции с мерами уголовно-правового характера. Раскрываются проблемы дифференциации родового и видового признаков мер уголовно-правового характера как мер государственного принуждения, выраженных в ограничениях или лишениях прав и свобод лица, фактически совершившего общественно-опасное деяние, предусмотренное Особенной частью Уголовного кодекса РФ, в целях предупреждения его повторного совершения. Автором конструируется комплекс уголовно-правовых мер, в который входят принудительные меры медицинского характера, конфискация имущества, принудительные меры воспитательного воздействия, ограничения, применяемые к условно освобожденным от наказания. Раскрывается каждый элемент представленной системы в эвристической плоскости.
\end{abstract}

Ключевые слова: наказание, иные меры, уголовное законодательство, уголовно-правовой характер, уголовноправовые последствия, мера уголовно-правового характера, конфискация имущества, принудительные меры воспитательного воздействия.

DOI: $10.35634 / 2412-9593-2019-29-6-868-876$

Ученые в своих научно-исследовательских работах прямо или косвенно затрагивали данную проблему, например, А.Н. Батанов [1], М.Ф. Гареев [4], Т.М. Калинина [7], С.Г. Келина [9], Н.Ю. Скрипченко [13] и многие другие. Но во всех этих научных изысканиях есть существенное упущение: одни ученые рассматривают только проблему наказания как отдельного института уголовного права, другие - исключительно иные меры уголовно-правового характера, третьи - и наказание, и иные меры уголовно-правового характера. Иными словами, они исследуют отдельные видыэлементы, но при этом практически никто из них, за редким исключением разве что И.Э. Звечаровского [6] и некоторых других, не делает ни шага в сторону обобщения и поиска общей категории, некоего единого начала, из которого и произошли понятия «наказание» и «иные меры». Нам представляется более целесообразным изучить, прежде всего, не отдельные разновидности, а обобщающую категорию - меры уголовно-правового характера. Это связано с тем, что наказание и иные меры уголовно-правового характера, их особенности детерминируются, определяются именно признакамиособенностями, присущими «родовому» понятию (т. е. понятию, на которое направлено деление) мерам уголовно-правового характера. Безусловно, мы не отрицаем того, что необходимо исследовать всю глубину и наказания, и иных мер уголовно-правового характера по отдельности и вместе, во всей их совокупности и взаимодействии. Но, на наш взгляд, это возможно лишь в условиях, когда исследован «родовой» термин сам по себе.

С самых давних времен был известен отдельный вид уголовно-правовых мер - наказание. Так, например, еще в Русской Правде указывались различные карательные меры в качестве наказания за совершение преступления. А вот другие виды мер, особенности которых будут рассмотрены далее, не были известны вплоть до принятия Уголовного кодекса РСФСР 1960 г., ${ }^{1}$ определившего в гл. 6 Общей части принудительные меры медицинского и воспитательного характера. И лишь с принятием Уголовного кодекса РФ 1996 г. (далее - УК РФ) категориальный аппарат уголовного права обогатился целым рядом понятий, ранее либо вообще не известных, либо встречавшихся лишь в теоретических научных исследованиях. К таковым следует отнести и меру уголовно-правового характера [12].

\footnotetext{
${ }^{1}$ Уголовный кодекс РСФСР (утв. ВС РСФСР 27.10.1960) // Ведомости ВС РСФСР. 1960. № 40. Ст. 591.
} 
Но сразу хочется отметить, что депутаты Государственной Думы также не идеальны. Иными словами, не только теоретики уголовного права совершают вышеописанную ошибку, но и сам законодатель идет по пути практически всех ученых, занятых этой проблемой, употребляя в ч. 2 ст.2 УК РФ термины «наказание и иные меры уголовно-правового характера» (именно «иные меры» как разновидность, а не «меры» в целом). Подводя итог вышесказанному, следует отметить, что именно в Уголовном кодексе РФ 1996 г. появилась само словосочетание «мера уголовно-правового характера», но, к сожалению, лишь в контексте иных мер как альтернативы наказанию.

Итак, перейдем к определению столь сложной категории. По нашему мнению, первоначально следует провести лингвистический анализ каждого слова в отдельности. Согласно Толковому словарю русского языка под редакцией Д.Н. Ушакова [15], слово «мера» имеет несколько значений: вопервых, единица измерения протяжения или емкости (например, мера длины); во-вторых, предел, граница, размер (как пример, знать меру); в-третьих, мероприятие, способ действия (принять меры предосторожности). В нашем случае наибольший интерес представляет именно третий пункт, то есть под мерами следует понимать некие мероприятия, что в Толковом словаре русского языка И. С. Ожегова и Н.Ю. Шведовой [14] означает совокупность действий, объединённых одной общественно значимой задачей, целью. Уголовно-правовой характер, согласно Большому российскому энциклопедическому словарю [3], следует трактовать как отличительное свойство, особенность, качество вышеописанных мер, предусмотренных исключительно сферой уголовного права или, точнее говоря, УК РФ как его основой. Таким образом, с точки зрения русского языка меры уголовно-правового характера есть не что иное, как совокупность действий, объединённых общей целью-задачей и предусмотренных уголовным законодательством нашей страны. Да, безусловно, о мерах уголовно-правового характера идет речь не только в Уголовном кодексе, но и в Уголовно-процессуальном, и Уголовноисполнительном кодексах. Но в двух последних речь идет не о мерах уголовно-правового характера в их собственном смысле в рамках материального права: особенностях, видах, основаниях применения. В них, по нашему мнению, имеется в виду порядок их применения (в УПК - о назначении судом за совершенное преступление, в УИК - о порядке реализации их на практике, лучше сказать, о претворении в жизнь уже назначенных мер - исполнении).

Теперь перейдем непосредственно к теоретическим изысканиям в данной сфере. Так, Е.В. Благов дает следующее определение исследуемой категории: под мерами уголовно-правового характера допустимо понимать уголовно-правовые последствия признания преступности общественно опасного деяния [2]. Данное определение страдает рядом неточностей: во-первых, автор, говоря «меры уголовно-правового характера», подразумевает «иные меры», а не меры в целом. Таким образом, не используя слово «иные», он недооценивает содержащуюся в нем специфику «иных мер» по отношению к наказанию. Во-вторых, прямым последствием признания преступности деяния все же является вопрос об уголовной ответственности, а уже за ним следуют вопросы о наказании и/или иных мерах уголовно-правового характера. Так, если вопрос об уголовной ответственности решается положительно, тогда уже возникает вопрос о мерах. Если вопрос решится отрицательно, то следует освобождение и от уголовной ответственности, и, следовательно, от мер. В-третьих, если утверждать о существовании уголовно-правовых последствий, то логично предположить, что помимо уголовноправовых последствий существуют и другие. Гражданско-правовые, административно-правовые? Нам же представляется, что таковых нет. Возможно, автор имел в виду психологический аспект или же невозможность заниматься впоследствии деятельностью в сфере образования. В-четвертых, не известно, на кого или кому направлены эти последствия, то есть, по мнению Е.В. Благова, существует некое абстрактное (ни к кому не привязанное) деяние, которое обладает достаточно высокой степенью общественной опасности, чтобы оно было признано преступлением. Он ни слова не говорит о том, к кому будут применяться эти меры: к лицу, которое совершило деяние, или к кому-то другому или, возможно, к обществу в целом. И наконец, по-прежнему остается нерешенным вопрос: в чем же содержание этих последствий.

Известный теоретик уголовного права И.Э. Звечаровский в своей статье «Меры уголовноправового характера: понятие, система, виды» дает свое определение исследуемого термина: мерами уголовно-правового характера следует признать меры, предусмотренные уголовным законом, которые применяются независимо от юридической природы поведения лица, совершившего преступление, но с учетом изменений в его уголовно-правовом статусе [5]. Безусловно, И.Э. Звечаровский достоин уважения за попытку ввести в юридическую науку объединяющую категорию - меры уголовно- 
правового характера. Но, к сожалению, его определение также не лишено ошибок. И, на наш взгляд, эффективней будет разобрать его по частям - признакам и выявить их изъяны.

Во-первых, к числу мер уголовно-правового характера следует относить только те из них, что предусмотрены уголовным законом, которые сами по себе являются уголовно-правовыми. Другими словами, это те меры, применение которых влечет за собой изменение уголовно-правового статуса личности. Но тогда придется исключить из списка иных мер, указанные в гл. 14 и 15 УК РФ, меры воспитательного воздействия, применяемые к несовершеннолетним, и принудительные меры медицинского характера, поскольку они никоим образом не влияют на уголовно-правовой статус лица.

Во-вторых, автор задает вопрос: что является основанием для их применения, то есть вследствие каких обстоятельств они могут быть назначены. По мнению И.Э. Звечаровского, они могут быть вызваны как противоправным, в том числе преступным, так и правомерным поведением. Но в ч. 2 ст. 2 УК РФ указано, что эти меры устанавливаются только за совершение преступления. Точнее говоря, не за сам факт совершения преступления, а за уже оконченное преступление, поскольку возможен добровольный отказ, не порождающий уголовной ответственности, а значит, и применение мер уголовно-правового характера. Также следует отметить, что есть не только основная причина, но и дополнительные юридические фактыусловия, отличные по ситуации. Так, например, для применения мер медицинского характера требуется не только факт совершения преступления, но и определенное психическое состояние преступника, предусмотренное в ч. 1 ст. 97 УК РФ, а для мер воспитательного воздействия требуется, чтобы лицо, совершившее преступление, было несовершеннолетним.

В-третьих, как отмечает И.Э. Звечаровский, по общему правилу, к мерам уголовно-правового характера относятся те, которые влекут изменение уголовно-правового статуса субъекта вследствие поведения, имеющего уголовно-правовое значение. С этим в целом можно согласиться. Действительно, поведение влияет на применение рассматриваемых мер, но не любое, а только преступное. Это обусловлено словами «уголовно-правовой характер». Так, например, составление завещания, то есть поведение, имеющее гражданско-правовое значение, никак не может порождать назначение мер уголовно-правового характера.

Прежде чем говорить о видовых признаках, по нашему мнению, следует выяснить родовой признак. Так, например, наказание имеет своим родовым признаком «меру государственного принуждения». В общем, с некоторыми допущениями для мер уголовно-правового характера данный род может подойти. Стоит его охарактеризовать. Для этого нужно вернуться к «корням», то есть к русскому языку, и раскрывать этот родовой термин как «совокупность действий, объединённых одной общественно значимой задачей, целью». Причем эти действия выражаются в неких обязанностях и ограничениях.

Также стоит упомянуть и про сам характер и содержание мер. Различные правовые меры применяются в связи с совершением правонарушений, отличающихся характером и степенью вредоносности. Соответственно, этим и определяется характер самих мер [8]. Из этого следует, что уголовноправовой характер мер определяется не только наличием запретов в уголовном законодательстве, но и характером общественной опасности и типом правонарушения, совершаемого лицом, что еще больше способствует возможности отделить их от административно-правовых мер.

Что касается содержания, то суть мер уголовно-правового характера заключается в ограничении или лишении прав и свобод лица. Несмотря на то что эти права и свободы дарованы Конституцией РФ и никто не может посягать на их, сама же Конституция указывает на возможность ограничения прав. Так, в ч. 3 ст. 55 Конституции РФ говорится, что «права и свободы человека и гражданина могут быть ограничены федеральным законом (в нашем случае Уголовным кодексом РФ. - К.A.) только в той мере, в какой это необходимо в целях защиты основ конституционного строя, нравственности, здоровья, прав и законных интересов других лиц, обеспечения обороны страны и безопасности государства».

При этом никто из авторов не затрагивает вопроса о субъектах и порядке применения мер, что, на наш взгляд, является достаточно существенными, и о них стоит упомянуть, но в материальное уголовно-правовое (а не уголовно-процессуальное) определение вносить не стоит. Ведь они также являются отличительными видовыми признаками мер. Конечно, мы понимаем, что эти вопросы охватываются уголовно-процессуальным и уголовно-исполнительным законодательствами, но они также способствуют возможности различать меры различной принадлежности. Безусловно, субъектом применения является государство, различные органы которого участвуют в процессе реализации мер. Это отличает наказание как вид мер уголовно-правового характера от, например, наказания детей в семье. Причем реализация этих мер проходит в несколько этапов: назначение и непосредственное 
применение на практике - исполнение. Это и определяет субъектный состав. Так, назначение производится судом, следовательно, меры, назначенные не судом, не могут являться мерой уголовноправового характера. Исполнение осуществляют органы системы Федеральной службы исполнения наказания и иными специализированными учреждениями (например, специальным учебновоспитательным учреждениям закрытого типа органов управления образованием). Но если назначенные меры не исполняются или исполняются ненадлежащим образом, то в дело вступают правоохранительные органы. Это позволяет говорить о направленности на принуждение к этим мерам.

Таким образом, мера уголовно-правового характера - это мера государственного принуждения, выраженная в ограничении или лишении прав и свобод лица, фактически совершившего общественно-опасное деяние, предусмотренное Особенной частью Уголовного кодекса РФ, в целях предупреждения его повторного совершения.

Учитывая тот факт, что практически никто из авторов не дает развернутой классификации и четкого перечня всех мер уголовно-правового характера, мы попытаемся не только назвать их, но и раскрыть их содержание. Более того, в юридической науке существуют и ошибочные мнения и, соответственно, ошибочные перечни исследуемых мер. Поэтому мы также рассмотрим наиболее типичные ошибки. В связи с тем, что авторы не вводят обобщенную категорию, следовательно, они остановились в развитии классификаций, то есть выделяют лишь один, безусловно, основополагающий, базовый вид мер уголовно-правового характера, но, на наш взгляд, необходимо выделить и другие. Сразу хочется отметить, что у каждого вида существует еще несколько подвидов, тем самым образуется целая система.

Вслед за ведущими учеными мы также начнем с основополагающей классификации. Для начала введем критерий, по которому происходит деление. Рассмотрим ч. 1 ст. 6 УК РФ, согласно которой наказание и иные меры уголовно-правового характера, применяемые к лицу, совершившему преступление, должны быть справедливыми, то есть соответствовать характеру и степени общественной опасности преступления, обстоятельствам его совершения и личности виновного. Поэтому в качестве критерия мы можем использовать характер и степень совершенного деяния и личность виновного. В соответствии с ним следует выделять наказание и иные меры уголовно-правовые характера. Безусловно, такая формулировка сложна для применения на практике, поскольку не известно, какие именно меры и какой смысл вкладывал законодатель в понятие «иные меры», вводя их в законодательство. С одной стороны, он открывает перечень этих мер, но не включает в него все необходимые, а лишь «принудительные меры медицинского характера» и «конфискацию имущества», с другой стороны, под иными мерами законодатель мог иметь в виду меры, отличные от наказания, точнее его альтернативу. Если он говорит, то это является крайне неэффективным и порождает множество ошибок.

Итак, перейдем непосредственно к классификации - дадим характеристику каждого вида в отдельности и выделим соответствующие подсистемы.

Что же такое наказание и какие виды наказания существуют? Относительно наказания как самостоятельного института в уголовном праве написано множество научных исследований. Рассмотрим его с точки зрения законодательства и теории. Согласно, ч. 1 ст. 43 «наказание есть мера государственного принуждения, назначаемая по приговору суда. Наказание применяется к лицу, признанному виновным в совершении преступления, и заключается в предусмотренных настоящим кодексом лишении или ограничении прав и свобод этого лица».

Для начала определимся с признаками «иных мер» и с порядком их применения. Как и у наказания, основанием является совершение деяния, признаваемого уголовным законодательством в качестве преступления. Но, в отличие от наказания, некоторые виды мер могут применяться к лицам, лишь фактически совершившим преступление. Иными словами, лицо, совершившее преступление, не может в силу возраста или психического состояния признаваться преступником. Так, если наказанию всегда предшествуют преступление и уголовная ответственность, то лицо, подвергнутое «иным мерам», не всегда юридически совершало преступление. Суть мер заключается в ограничениях или лишениях, но от наказания они отличаются уровнем. Например, «ограничения, применяемые к условно освобожденным от наказания» несут не такие серьезные ограничения свободы, как, например, арест. В первом случае подвергнутое наказанию лицо в общем понимании находится на свободе, но не может менять место жительства, посещать определенные места в определенное время суток и некоторые другие, предусмотренные ч. 5 ст. 73 УК. Во втором случае лицо изолируется от общества, то есть его контакт с обществом ограничен. 
Если все виды наказания, взятые в совокупности, образуют систему (как в ст. 44 УК), то иные меры - это комплекс мер. Согласно п. 2 Постановления Пленума Верховного Суда РФ от 11.01.2007 «О практике назначения судами Российской Федерации уголовного наказания» ${ }^{2}$, «виды уголовного наказания в УК РФ расположены в определенной последовательности от менее строго к более строгому». С иными мерами подобной системы нет, они оторваны друг от друга. Поэтому в отношении них можно говорить, что они образуют не систему, а комплекс мер. В него-то и входят 4 вида иных уголовно-правовых мер:

- принудительные меры медицинского характера;

- конфискация имущества;

- принудительные меры воспитательного воздействия;

- ограничения, применяемые к условно освобожденным от наказания.

Как и наказания, иные меры можно подразделить на самодостаточные и несамодостаточные. Первые будут применяться в качестве самостоятельных мер как альтернатива наказанию и освобождающие от уголовной ответственности или наказания. Например, принудительные меры воспитательного воздействия при некоторых условиях применяются к несовершеннолетним вместо наказания. Вторые - в качестве дополнения к наказанию, то есть вместе с наказанием. Например, конфискация имущества применяется наряду с основным наказанием или принудительные меры медицинского характера, соединенные с исполнением наказания.

Как следует из наименования, данный вид иных мер напрямую зависит от освобождения от наказания под условием применения рассматриваемых мер. Сюда можно отнести ограничения, налагаемые в связи: 1) с условным осуждением (ст. 73); 2) условно-досрочным осуждением (ст. 79); 3) отсрочкой отбывания наказания (ст. 82); 4) отсрочкой отбывания наказания больным наркоманией $\left(\right.$ ст. $\left.82^{1}\right)$. Вкратце рассмотрим каждый из них.

1. Если суд при рассмотрении уголовного дела приходит к выводу о возможности достижения целей наказания без реального отбывания наказания, то он постановляет считать назначенное наказание условным. По своему содержанию условное осуждение не является наказанием в прямом значении этого слова, хотя и именуется «условным наказанием». Такое наказание заключается в установлении испытательного срока, в течение которого условно осужденный должен своим поведением доказать свое исправление. Но в дополнение к наказанию на него могут быть возложены дополнительные ограничения, призванные способствовать исправлению. Эти ограничения и являются иной мерой уголовно-правового характера. Они содержатся в ч.5 ст. 73 Уголовного кодекса РФ и налагаются с учетом трех характеристик осужденного: возраста, трудоспособности и здоровья. Перечень таких обязанностей является открытым и может включать, например, обязанность не менять постоянного места жительства, работы, учёбы, не посещать определённые места, пройти курс лечения от алкоголизма, наркомании, токсикомании или венерического заболевания, осуществлять материальную поддержку семьи и другие.

В большинстве случаев на практике эти ограничения назначаются в совокупности. Так, в одном из приговоров на условно осужденного Б. были возложены обязанности «являться на регистрацию в специализированный государственный орган, осуществляющий контроль за поведением условно осужденного, по месту жительства, ежемесячно, в сроки установленные инспектором; не менять постоянного места жительства без уведомления специализированного государственного органа, осуществляющего контроль за поведением условно осужденного; не злоупотреблять спиртными напитками; не совершать административные правонарушения, связанные с нарушением общественного порядка» ${ }^{3}$.

При назначении условного наказания суд устанавливает специализированный государственный орган, осуществляющий контроль за поведением условно осужденного, который контролирует соблюдение возложенных ограничений. Согласно ч. 1 ст. 47.1 Уголовно-исполнительного кодекса РФ, специализированным государственным органом, осуществляющим надзор за отбыванием осужденными наказания в виде ограничения свободы, является уголовно-исполнительная инспекция. Их статус регламентирован Положением «Об уголовно-исполнительных инспекциях».

\footnotetext{
${ }^{2}$ См.: Постановление Пленума Верховного Суда РФ № 2 от 11 января 2007 г. «О практике назначения судами Российской Федерации уголовного наказания» // Бюллетень Верховного Суда РФ. 2007. № 4.

${ }^{3}$ См.: Дело № 1-30/2013. Архив Ярославского районного суда Ярославской области за 2013 год.
} 
2. Если для своего исправления лицо, отбывающее содержание в дисциплинарной воинской части, принудительные работы или лишение свободы, не нуждается в полном отбывании назначенного судом наказания, то он подлежит условно-досрочному освобождению. Для данного вида освобождения требуются такие важные условия, как лицу был назначен определенный вид наказания и осужденный не нуждается в полном отбывании наказания.

Как определяет ч. 2 ст. 79 Уголовного кодекса РФ, к досрочно освобожденным применяются ограничения, предусмотренные ч. 5 ст. 73. Их мы уже характеризовали выше при описании условного освобождения.

3. Что касается отсрочки отбывания наказания по ст. 82 УК РФ, то там также предусмотрены определенные ограничения. Осужденным: беременной женщине, женщине, имеющей ребенка в возрасте до четырнадцати лет; мужчине, имеющему ребенка в возрасте до четырнадцати лет и являющемуся единственным родителем; кроме осужденных к ограничению свободы, к лишению свободы за преступления против половой неприкосновенности несовершеннолетних, не достигших четырнадцатилетнего возраста, к лишению свободы на срок свыше пяти лет за тяжкие и особо тяжкие преступления против личности, суд может отсрочить реальное отбывание наказания до достижения ребенком четырнадцатилетнего возраста. Для данного вида освобождения необходимо наличие ряда условий: 1) определенное лицо, к которому будет применяться данная мера уголовно-правового характера; 2) определенные преступление и наказание; 3) у лица должен быть ребенок, которому еще не исполнилось 14 лет. В данном случае также можно наблюдать условное освобождение от наказания, точнее, от его отбытия. При этом на освобожденное лицо налагаются ограничения, пусть и не такие явные, как при вышеописанных случаях, а именно, обязанности по воспитанию, заботе о ребенке, но если он не будет исполнять эти обязанности, то ему будет отменено освобождение и возвращено реальное наказание.

4. Осужденному к лишению свободы, признанному больным наркоманией, совершившему впервые преступление, предусмотренное ч. 1 ст. 228 , ч. 1 ст. 231 и ст. 233 настоящего Кодекса, и изъявившему желание добровольно пройти курс лечения от наркомании, а также медико-социальную реабилитацию, суд может отсрочить отбывание наказания в виде лишения свободы до окончания лечения и медико-социальной реабилитации, но не более чем на пять лет. Освобождение по данной статье возможно, если: 1) лицу назначено наказание в виде лишения свободы; 2) лицо должно быть признано больным наркоманией; 3) преступление должно быть совершено впервые и только предусмотренное определенными статьями; 4) лицо должно изъявить желание пройти курс лечения от наркомании. Также устанавливаются временные рамки для лечения. Лишь при наличии данных условий в совокупности можно идти речь об освобождении от наказания по данному основанию с одновременным возложением на осужденного ограничений в виде прохождения курса лечения.

Следует отметить, что не всякий вид освобождения, предусмотренный в гл. 12 УК, является мерой уголовно-правового характера. К таковым относятся замена неотбытой части наказания более мягким видом наказания (ст. 80), освобождение от наказания в связи с изменением обстановки (ст. $80^{1}$ ), освобождение от наказания в связи с болезнью (ст. 81), освобождение от отбывания наказания в связи с истечением сроков давности обвинительного приговора суда (ст.83). Их нельзя отнести к мерам «ограничения, применяемым к условно освобожденным от наказания», так как нет никакого принуждения и взамен наказания не устанавливается никаких ограничений. Например, при освобождении по ст. 81 лицо страдает болезнью, которая несовместима в данный момент с реальным отбытием наказания, и, излечившись, оно будет отбывать назначенное наказание, если не истекли сроки давности.

Как представляется, в первую очередь, необходимо определиться с терминами «цель» и «значение». Согласно Толковому словарю русского языка И.С. Ожегова и Н.Ю. Шведовой, цель - это предмет стремления, то, что надо, желательно осуществить. Толковый словарь русского языка Д.Н. Ушакова определяет, что значение - это влияние, общественная роль исследуемого явления.

В Уголовном кодексе закреплены различного рода цели. Определим цели каждого из видов. Например, если допустить тождество терминов «цель» и «задача», то в ст.2 закреплены цели всего уголовного законодательства: охрана прав и свобод человека и гражданина, собственности, общественного порядка и общественной безопасности, окружающей среды, конституционного строя Российской Федерации от преступных посягательств, обеспечение мира и безопасности человечества, а также предупреждение преступлений.

Согласно ч. 2 ст. 7 УК РФ, наказание и иные меры уголовно-правового характера, применяемые к лицу, совершившему преступление, не могут иметь своей целью причинение физических страданий или унижение человеческого достоинства. 
Цели наказания и иных мер уголовно-правового характера исследовали такие ученые, как С.В. Максимов [10] и Т. Ф. Минязева [11]. Согласно ч. 2 ст. 43 УК РФ, целями наказания являются восстановление социальной справедливости, исправление осужденного и предупреждение совершения новых преступлений. Рассмотрим подробнее каждую из них.

Восстановление соииальной справедливости. В чем же содержание данной цели? Лицо нарушает общественное спокойствие, причиняет ему вред и, тем самым, влияет на «баланс» между тем, что совершило лицо, характером причиненного вреда, и воздаянием за это деяние. Подобно тому, как за добросовестный труд работнику выплачивается его заработная плата. Потому общество и должно его наказать и восстановить «баланс». В обществе еще с советского периода господствует аксиома, что за преступлением всегда должно следовать наказание. В этом-то и состоит принцип справедливости.

Что же касается второй цели - исправление осужденного? Преступив закон, лицо, как говорится, встало на кривую дорожку, совершает ошибку, у него появляются недостатки, какие-то пороки. Наказав его, государство и общество пытаются исправить его, скорректировать, вернуть на «путь истины», освобождают от этих пороков. После того, как преступник отбудет свое наказание, он, в теории, должен выйти морально свободным, «чистым» перед собой и обществом. Считается, что в результате совершения преступления повреждается, травмируется, страдает психика данного лица. И наказывая его, общество «залечивает» его. Но только, к сожалению, на практике не всегда выходит так, как это было задумано изначально.

С этой связана другая цель - предупреждение совершения новых преступлений. Исполнив назначенное наказание, лицо, опять же в идеале, не должно желать совершать новое преступление и, следовательно, опять нести новое, причем более строгое как за рецидив, наказание. И вряд ли лицо, хотя бы раз побывавшее в исправительном учреждении, не будет желать попасть туда обратно.

Немного сложнее дело обстоит с целями иных мер уголовно-правового характера, поскольку нигде в Уголовном кодексе не говорится, какие же цели преследуют иные меры в целом, и лишь у некоторых отдельных видов «иных мер» оговорены их цели.

Так, по ст. 98 УК принудительные меры медицинского характера преследуют, как нам кажется, две: медицинскую и уголовно-правовую цели. Медицинская заключается в излечении лиц или улучшении состояния их здоровья. Так, С. В. Максимов пишет, что излечение означает выздоровление лица, то есть полное исчезновение психического расстройства. Это так называемая программамаксимум. Чего можно добиться с помощью принудительных мер медицинского характера. Уголовно-правовая же - в общей и частной превенции, в предупреждении совершения новых преступлений.

Конфискация имущества имеет несколько целей. Прежде всего, это компенсационная, то есть возмещение законным владельцам вреда, причиненного преступлением. К таковым владельцам следует относить публично-правовые образования (Российская Федерация, субъект РФ, муниципальное образование), физические и юридические лица. Нам кажется, что также можно выделять цุель превенции, заключающуюся в изъятии орудий совершения преступления, принадлежащих обвиняемому, дабы у него не было средств для совершения новых преступлений. Также можно проследить экономическую цель в пополнении доходов государства за счет конфискованного имущества. Примером тому может служить конкретный приговор. «Согласно п. «а» ч. 1 ст. 104.1, ст. 104.2 УК РФ имущество, полученное Т. в результате совершения преступлений, предусмотренных ст. 290 УК РФ, а именно, денежную сумму, соответствующую размеру полученных им взяток - 240000 (двести сорок тысяч) рублей, конфисковать у Т. в собственность государства» ${ }^{4}$. Так, в результате применения конфискации в данном деле бюджет России увеличился на 240 тыс. рублей.

Принудительные меры воспитательного воздействия имеют две цели: учебно-воспитательная и превентивная. Учебно-воспитательная состоит в том, что привлечение несовершеннолетнего к уголовной ответственности и отбытие наказания может сказаться на его психике, «сломав», «разрушив», «надломив» ее. А применение указанных мер не окажет такого воздействия, и несовершеннолетний сохранит нормальное психическое состояние, но при этом он поймет отрицательное воздействие своего деяния. Превентивная цель заключается в том, чтобы лицо исправилось и впредь не совершало новых преступлений.

Ограничения, применяемые к условно освобожденным от наказания, преследуют также свои цели: воспитательная, экономическая, превентивная и обеспечение эффективного контроля. Воспи-

\footnotetext{
${ }^{4}$ См.: Дело № 2-20/2012. Архив Ярославского областного суда за 2012 год.
} 
тательная цель заключается в следующем. Помимо испытательного срока налагаются сверх того дополнительные обязанности. Это необходимо, чтобы условно освобожденный понял, что хоть он и освобожден от наказания, но все же по сути подвергнут наказанию, чтобы он понял всю тяжесть своего положения, чтоб не считал, что он избежал ответственности, и затем уже не совершало преступных деяний. Также представляется возможным выделить цели, согласно которой данное лицо будет направлено в мирное русло. В том смысле, что освобожденный, которому будет назначена данная мера, например, в форме обязанности трудиться (трудоустроиться) или обучаться, то лицо будет задействовано в трудовой деятельности, тем самым будет «отвлечено» от преступной деятельности. В этом состоит экономическая цель. А если, скажем, будет назначена обязанность не менять место жительства, то цель меры состоит в том, чтобы обеспечить более эффективный контроль за условно освобожденным. Поскольку специализированному органу проще осуществлять свои функции, когда подопечный находится «в пределах видимости». Да и, по нашему мнению, у условно освобожденного может возникнуть соблазн совершить преступление в другом месте своего жительства без контроля со стороны государства. Подобным образом реализуется цель эффективного контроля. Также, безусловно, следует выделить цель превенции, как общую цель мер уголовно-правового характера.

Таким образом, следует выделить цели для мер уголовно-правового характера в целом. Проанализировав отдельные виды мер, определив их цели, можно выделить одну общую цель всех мер предупреждение повторного совершения общественно опасных деяний, предусмотренных Особенной частью Уголовного кодекса.

\section{СПИСОК ЛИТЕРАТУРЫ}

1. Батанов А.Н. Иные меры уголовно-правового характера - самостоятельный институт российского уголовного законодательства? // Общество и право. 2011. № 5.

2. Благов Е.В. Общая часть уголовного права в 20 лекциях: курс лекций. М.: Юрлитинформ, 2012. 344 с.

3. Большой российский энциклопедический словарь. URL: http://www.dict.t-mm.ru/all/harakter.html

4. Гареев М.Ф. Цели иных мер уголовно-правового характера и средства их достижения по российскому праву: дис. ... канд. юрид. наук. Казань, 2005.

5. Звечаровский И.Э. Меры уголовно-правового характера: понятие, система, виды // Законность. 2014. № 3. C. $36-39$

6. Звечаровский И.Э. Понятие мер уголовно-правового характера // Законность. 2007. №1. С. 19-21.

7. Калинина Т.М., Палий В.В. Иные меры уголовно-правового характера: научно-практический комментарий / отв. ред. А.И. Чучаев. М.: Проспект, 2011. 152 с.

8. Каплин М.Н. О мерах уголовно-правового характера. // Актуальные проблемы дифференциации ответственности и законодательная техника в уголовном праве и процессе. Ярославль, 2013. С. 169-176.

9. Келина С.Г. Наказание и иные меры уголовно-правового характера // Государство и право. 2007. № 6.

10. Максимов С.В. Цели принудительных мер медицинского характера // Российский следователь. 2016. № 12.

11. Минязева Т.Ф. Цели наказания и иных мер уголовно-правового характера и средства их достижения в современном уголовном праве // Законы России: опыт, анализ, практика. 2014. № 5. С. 81-87.

12. Полный курс уголовного права. Т. 1 / под ред. А.И. Коробеева. СПб., 2008. С. 701.

13. Скрипченко Н.Ю. Применение принудительных мер медицинского характера в отношении несовершеннолетних // Российский юридический журнал. 2012. № 4.

14. Толковый словарь русского языка / под ред. И.С. Ожегова и Н.Ю. Шведовой. М.: Азъ, 1992.

15. Толковый словарь русского языка: в 4 т. / под ред. Д.Н. Ушакова. Т. 1. М., 1935; Т. 2. М., 1938; Т. 3. M., 1939; T. 4, М., 1940. Репринтное издание: М., 1995; M., 2000. URL:http://ushdict.narod.ru/041/w12450.htm

Комоско Анна Александровна, кандидат юридических наук, заведующий кафедрой административного и уголовного права Среднерусский институт управления - филиал РАНХиГС 302027, Россия, г. Орел, ул. Панчука, 9

E-mail: komoskoanna@yandex.ru 


\section{A.A. Komosko CERTAIN PROBLEMS OF SENTENCING AND APPLICATION OF OTHER MEASURES OF A CRIMINAL-LEGAL NATURE UNDER THE RUSSIAN LEGISLATION}

DOI: $10.35634 / 2412-9593-2019-29-6-868-876$

The institution of punishment and other measures of a criminal law nature is important in the development of criminology and criminal law. However, in the scientific literature to date there is no single understanding of individual legal structures, which, of course, affects the formation of the core of the concept of punishment. The article discusses the problems of the appointment and application of other measures of a criminal law nature. Based on the analysis of scientific works of specialists in this field, the author draws conclusions that allow optimizing the categorical apparatus used in law enforcement. A new approach is given to the disclosure of the term "punishment", the position is justified, according to which the institution of punishment can only be studied through the prism of correlation with criminal law measures. The article discloses the problems of differentiation of the generic and species characteristics of criminal law measures as measures of state coercion, expressed in restrictions or deprivation of the rights and freedoms of a person who actually committed a socially dangerous act, provided for by the Special Part of the Criminal Code of the Russian Federation, in order to prevent its re-commission. The author constructs a complex of criminal legal measures, which include compulsory medical measures, confiscation of property, compulsory measures of educational influence, restrictions applied to those conditionally released from punishment. Each element of the presented system is revealed in the heuristic plane.

Keywords: punishment, other measures, criminal legislation, criminal-legal nature, criminal-legal consequences, measure of criminal-legal nature, confiscation of property, compulsory measures of educational influence.

Received 02.09.2019

Komosko A.A., Candidate of Law, head of Department of administrative and criminal law

Central Russian Institute of management - branch of Ranepa

Panchuka st., 9, Orel, Russia, 302027

E-mail: komoskoanna@yandex.ru 